\title{
A Web-Based Pilot Implementation of the Africanized Land Administration Domain Model for Kenya-A Case Study of Nyeri County
}

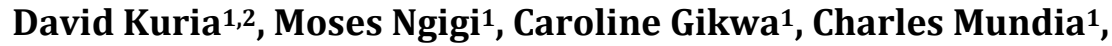 \\ Mary Macharia ${ }^{1}$ \\ ${ }^{1}$ Institute of Geomatics, GIS \& Remote Sensing, Dedan Kimathi University of Technology, Nyeri, Kenya \\ ${ }^{2}$ National Land Information Management Systems Directorate, National Land Commission, Nairobi, Kenya \\ Email:dn.kuria@gmail.com
}

Received 12 February 2016; accepted 11 April 2016; published 14 April 2016

Copyright @ 2016 by authors and Scientific Research Publishing Inc.

This work is licensed under the Creative Commons Attribution International License (CC BY). http://creativecommons.org/licenses/by/4.0/

(c) (i) Open Access

\begin{abstract}
Kenya has amassed a wealth of paper based land information records collected over the duration of more than a century. The National Land Commission (NLC) having the mandate to develop a National Land Information Management System (NLIMS) for Kenya partnered with the Dedan Kimathi University of Technology on a project to develop a pilot LIMS for Nyeri County. A pilot Land Administration System (LAS) has been developed in this work and utilizes an Africanized Land Administration Domain Model (A-LADM) fitted to the Kenyan context. Various processes involved in land administration that required to be automated were identified. Informed by the numbers of applications made for the change of User service, it was picked as the first workflow to be automated. The key outputs of this work were the A-LADM and pilot LAS. The pilot solution uses a webcentric solution, with the data stored and managed centrally from a PostGIS database backend, using the Python Django framework to implement the server side and client side frontend. This solution demonstrates the importance of automating processes and supporting standards based software development. Stakeholder participation is key when implementing systems and 2 workshops are held to capture requirements and validate the developed solution.
\end{abstract}

\section{Keywords}

LADM, LAS, A-LADM, Development Control, Workflow Automation 


\section{Introduction}

Kenya has amassed a huge collection of records since 1902 when the colonial government put in place the Crown Land Ordinance of 1902 [1]. This law allowed alienation of native lands for the colonial masters and the alienation process involved formal registration of ownership rights. Over the years, a number of laws touching on land have been passed and operationalized. This has resulted into having land administration and registration being exercised under different legislative regimes [2]. All the documentation produced from land transactions over these years has continued to be kept in paper form. This has seen a big number of these documents get destroyed by normal aging processes, lost through untracked paper trails and from corruption driven motives.

Recently, the National Land Policy was developed and recommended quite a number of radical steps in resolving land related issues [3]. This Policy identifies the various deficiencies that land administration and management experiences in Kenya. One of the key problems identified is the lack of an efficient, computer-based Land Information Management System (LIMS). The benefits of having Information Technology (IT) driven LIMS are numerous and can spur economic growth to levels unheralded. Through the promulgation of the Constitution, the passage of consolidated land laws, and the establishment of the National Land Commission (NLC), the strategies for the solution of the myriad of land related issues have been put in place. The NLC is the body by law mandated to develop, implement and maintain a nationwide land information management system, and it is taking a leading role in providing strategic direction in the actual implementation.

The basic building block in any Land Information System (LIS) is the land parcel as identified in the cadaster. The International Federation of Surveyors and Geodesists (FIG) defines a cadaster as a parcel based, and up-to-date land information system containing a record of interests in land (e.g. rights, restrictions, responsibilities and risks). It usually includes a geometric description of land parcels (cadastral maps) linked to other records describing the nature of the interests, the ownership or control of those interests, and often the value of the parcel and its improvements. It may be established for fiscal purposes (e.g. valuation and equitable taxation), legal purposes (conveyancing), to assist in the management of land and land use (e.g. for planning and other administrative purposes), and enable sustainable development and environmental protection.

Globally, Land administration and management has undergone a renaissance of sorts through the development and adoption of a number of standards governing it. Currently, the Land Administration Domain Model (LADM) is the prevailing ISO standard on land administration and management [4]. There are other principles and standards that have been formulated all geared towards reengineering land administration to make it responsive to technological advancements. These include the principles in Cadaster 2014 [5], focusing on formally recognized and registered or registrable parcels and the Social Tenure Domain Model (STDM) intended to handle the informal land holdings [6]. With the penetration of the Internet and smart devices, it is imperative that land administration on top of using these standard models in the design and formulation of its data models, should develop applications and services that utilize these technologies, thereby making information and services readily available to the Citizenry.

The overall goal of the project was to design and develop a pilot land administration and management system for Kenya. The data model behind the implementation was envisaged also to serve as a reference implementation of LADM in Africa. This model is an adaptation of the LADM to the local Kenyan context. To realize this goal, a set of objectives were developed, namely:

- Identification of the various data needs to support land administration in Kenya.

A number of entities are involved in land administration and management in the country, but the bulk of these have affiliations with the Ministry of Lands, Housing and Urban Development (MoLHUD), NLC and County Governments. The data needs of these entities were collected and collated to distil the actual information bits that should be processed by the system.

- Identification of various workflows involved in land transactions that can be captured, and identifying those that need to be incorporated in the pilot project

To achieve their various mandates, the entities dealing in land typically have procedures that are used in dayto-day operations. These have been captured in the form of business workflows and documented. Since not all of these could be implemented in the pilot, a number of them were shortlisted for implementation and the decision on which ones to implement was based on those that are fairly easy to implement and have maximum impact, given the limited time the project was supposed to have been concluded in.

- Mapping the information needs to the LADM and STDM employing Cadaster 2014 principles that are ap- 
plicable within the land registration framework that is in place.

The mapping sought to adapt these models to capture information in a form that tightly agrees with data pieces available and in conformity to prevailing laws governing the land sector in Kenya.

- Design and implement a pilot implementation of the modeled data and applications.

The data model developed was mapped to the eventual database used to store and manage both the spatial data and non-spatial data. From the list of workflows that have been implemented, a design of the system was done. This design has at its core a modular approach and the formulation of various functions and features following the Service Oriented Architecture (SOA). This allows the system to be extensible and able to plug into other SOA systems.

- Evaluate and propose scaling up strategy of the implemented pilot system.

The pilot developed was evaluated on its suitability to capture and manage the land information. Based on the evaluation, a proposal for the up scaling of the pilot has been presented, showing the phasing of workflow implementation and a pathway for full implementation to other governments and states that may be interested in implementing similar systems in their jurisdictions.

\section{Methods}

Figure 1 shows a schematic flow of the various steps undertaken in the implementation of the pilot system. It is broken into five main stages with each stage comprising of groups of activities. Data and information needs and system requirements were identified through desktop research coupled with questionnaires and interviews with anticipated end-users of the system. Data modeling involved the mapping and adapting of the various information pieces to the LADM in line with applicable Cadastre 2014 principles. The schema of models developed was migrated to a PostGIS database. Implementation data collected was digitized, edited and cleaned using QGIS. Additional soft data was also obtained, cleaned and edited in the QGIS environment. As this is the pilot implementation stage, it is expected that more data will be added to the system on a continuous basis.

Workflows identified during the needs and requirement identification stages were evaluated with reference to the impact and complexity of their implementation, from which a number of those favorable were considered for implementation in the pilot. The workflow that was decided was packaged in the form of services that will be exposed through the web application portal.

\subsection{Conceptual System Architecture}

Figure 2 captures the operational view of the various components that will comprise the fully developed NLIMS. All the data is being hosted at the NLC Data Center, which is accessed by the servers. For purposes of maintaining the data, administrative capabilities will be provided but which will be restricted to routine system maintenance and not tinkering with data held on the system. Members of staff of the Commission, the Ministry and/or the County, who will be generating data, modifying data and utilizing various workflows will access the

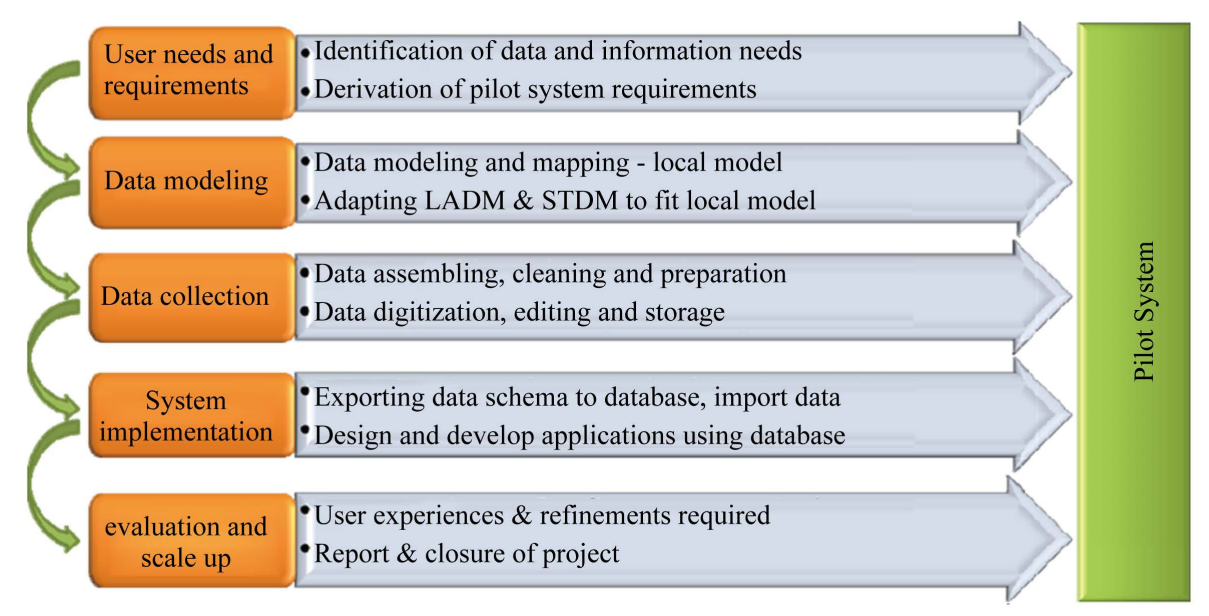

Figure 1. Flow of activities. 


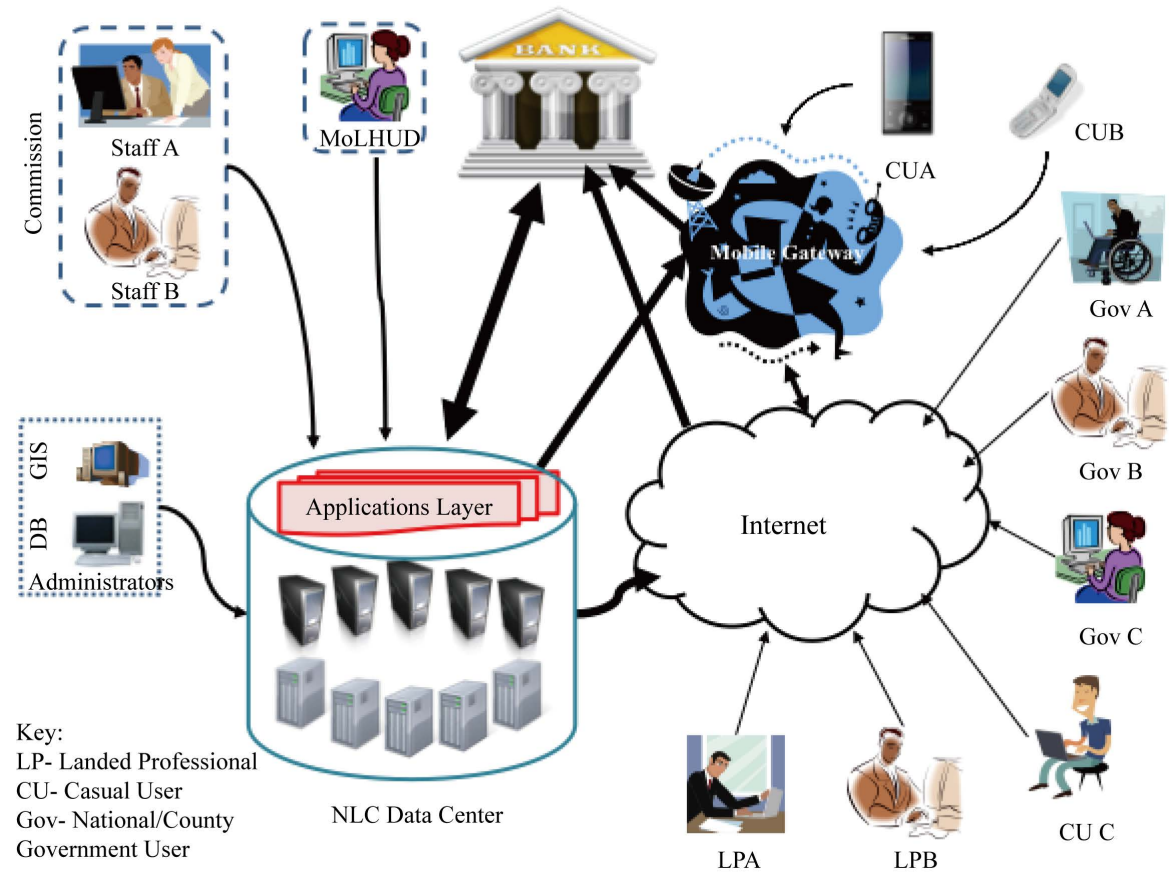

Figure 2. NLIMS implementation concept.

functionalities in the form well defined applications encapsulated in the applications layer. This application layer will be responsible for managing the interactions with the underlying GIS and database servers, which will inturn be reading from and writing to the NLC Data Center. Other users will interact with the system via the Internet through an online application portal that subsequently accessed the information via the application layer. Users can also gain access to functionalities of the system that will be delivered through a mobile gateway. This component is yet to be implemented but is in the implementation pipeline.

In order to gain insight on how to develop an effective and efficient land information management system and which addresses environmental control capabilities, the four types of questionnaires designed were: questionnaires for professional in the environmental agency, questionnaires for land professionals in private practice, questionnaires for county officers and questionnaires for land owners. The questionnaires were distributed and collected within a two-week period from 7 November 2014. The target sample size for each of the questionnaire type was 400.

\subsection{Methodology Adopted}

Questionnaires were developed to get information from stakeholders and players, identified as key in land transactions at the individual level or organizational level. In addition, desktop studies were conducted to help identify data needs and workflows, required in land transactions or business processes that access and use of land related data or information. Four types of questionnaires designed were: 1) questionnaires for professionals in environmental agencies, 2) questionnaires for land professionals in private practice, 3) questionnaires for county officers and 4) questionnaires for land owners. These questionnaires were distributed and collected within a two-week period from 7 November 2014. The target sample size for each of the questionnaire type was 400.

The results of these analyses were presented in a one-day workshop held in January 2015. The workshop's main objective was to discuss the user requirements and workflows that were in existence in the Kenyan land administration and management landscape. Figure 3 shows participants of the workshop during one of the sessions. Challenges faced in use of current systems, data needs, and propositions on what needs to be addressed in an improved LIMS were discussed, some of which are presented here in brief.

Respondents from environmental agencies suggested the following solutions 1) streamlining of the administrative processes, 2) abolishing of the land cartels, 3) Land adjudication of the whole country and conversion 


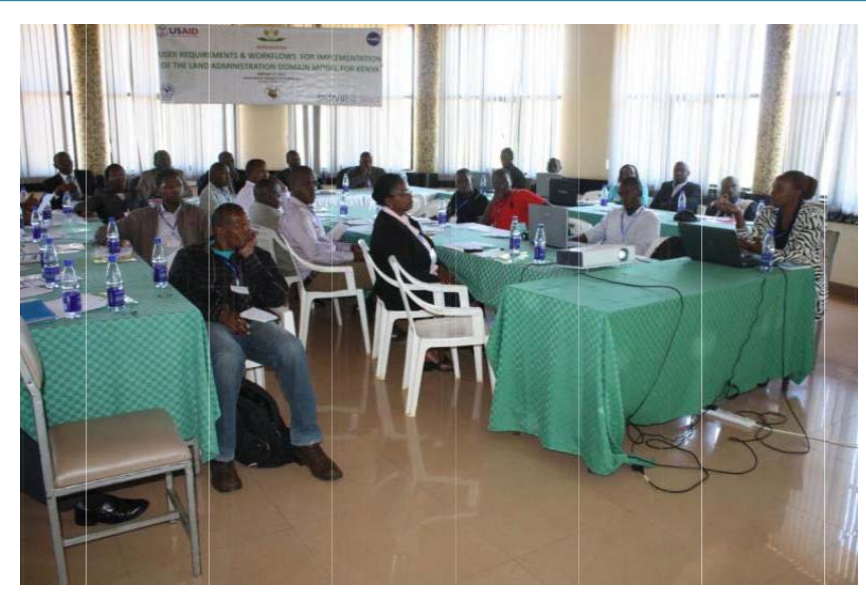

Figure 3. Participants of the workshop on user requirements and workflow analysis.

of all records to digital form 4) adequate funding to support the activities of the entities charged with land management, 5) enforcement of reserves e.g. riparian reserves, wayleaves, 6) improve quality of services, 7) subjection to heavy penalties to non-compliance with the law 8) build a state of the art technical services 9) provision of online and free access to land related data 10) educating the public on how to access land related information 11) enforcement of environmental protection policies 12) undertaking campaigns on environmental protection awareness 13) development of real time web based systems that give alerts, alarms and warnings, 14) reviewing of existing environmental regulations, 15) regulating land subdivision and managing land use changes, and 16) implementing Reducing Emissions from Deforestation and Forest Degradation (REDD+) strategies.

Respondents from the land management agencies identified the problems and challenges as: 1) corrupt dealings in land allocation, 2) cumbersome administrative processes, 3) lack of equipment/technology, and 4) ineffective regulations and laws. They proposed the following solutions to these challenges: 1) creation of transparent and accountable processes with sufficient supervision and regular system audit 2) digitization of all data, automation of all operations and removal of bureaucratic red tape in land information processing and access 3) training and competitively remunerating staff 4) purchase and use of state of the art equipment 5) formulation and enforcement of regulations to curb middlemen (cartels) in the land sector 6) formation of consortia drawn from government officials working in the land sectors and stakeholders drawn from this sector, having knowledge of land administration issues 7) creation and operationalization of a National Spatial Data Infrastructure (NSDI) with the enactment and enforcement of appropriate laws and regulations, and 8) creation of web portals exposing services allowing various transactions and enquiries on land information.

\subsection{Workflow Identification and Analysis}

An effective land administration system must determine, record and disseminate information about tenure, value, use and development of land. The Constitution of Kenya 2010 [7], the National Land Policy [3] and the National Land Commission Act [8] put in place a decentralized land administration system operating at both National and County level. The land administration workflows in use currently are still too centralized, bureaucratic and winding, a hindrance to effective and efficient service delivery. These workflows need to be reformed to address the current land people relationships trends which are influenced by dynamic changes in the society. This is inline with recommendations by [9], in support of land reforms by reforming core processes.

The LADM provides a good and standards based model that can be used to improve land administrative systems through the implementation of integrated land information management systems. The LADM can be used to model both formal and informal systems of land rights. Informal systems of land rights fit the STDM, which is a specialization of the LADM focusing on people-land relationships. An integrated LIMS that addresses both tenure systems is very appropriate. For the implementation of this system, existing workflows were evaluated to determine which can be prioritized for immediate development and those that can be queued for subsequent action. With the consolidation of the bulk of land laws to two, namely: the Land Act, 2012 [10] and Land Registration Act, 2012 [11], land administration and management functions have been eased from a legal framework 
standpoint. The recognition in law on the need to have LIMS in place makes it imperative to have a harmonized and integrated LIMS. Technological advancement has put web-centric and mobile-centric approaches to the fore, and these therefore need to be the platforms that this integrated LIMS solution will be delivered from and through.

The review on the many processes and workflows that use land information and services identified the following workflows that require harmonization across the spectrum of users, both actual and potential.

a) Land Administration Workflows, referring to those functions touching on land tenure, land valuation and taxation and land use control.

b) Valuation Workflows serving a number of purposes: generating public revenue, servicing of land, facilitation efficient utilization of land, providing incentives for appropriate land uses and discouraging land speculation.

c) Land Adjudication Workflows that confirm and confer land ownership on parties already occupying unadjudicated land.

d) Settlement Workflows used to identify land to settle the poor, and formally settle them.

e) Survey Workflows that are used to apportion land rights to parties. This is through land subdivision and survey of land parcels.

f) Physical/Landuse Planning Workflows supporting formulation of national and county spatial development plans and integrated planning approaches.

\subsection{Workflows Harmonization}

This research identified the various players of land related information and services. In order to concretize and harmonize the workflows, it is essential to define the following with respect to workflows: 1 ) identification of all players in a workflow, 2) identification of all activities in the workflow, 3) determination of security (access rights) level required for each activity, 4) sequencing of all activities logically, 5) allocation of access rights to each player for relevant activities, 6) ensuring that at every activity level that prior activities have been executed before attempting to act, 7) keeping track of actions taken, timelines and players involved, 8) allowing for overturning prior decision by authorized players and documentation of such modification

The main principles that this research recommended in the integration and harmonization processes are given as follows:

- Common "things" should be grouped together. This refers to activities, processes or components that are common across various workflows e.g. titling, opening new files for filing different documents according to requested services.

- Uncommon "things" can be separate but need to be able to communicate to one another on a need basis.

- Processes with portions overlapping should be disaggregated and overlapping portions treated as common "things". These should then be linked to the other portions to support seamless integration.

- Break processes to smaller chunks that can be chained together. These will be easier to maintain and modify while retaining overall functionality.

\section{Database and System Modeling}

The basic fabric of a land information system is an inventory of data on the spatial representation of legal land objects coupled with their attributes. It is the heart of the system and needs to be addressed from a number of perspectives including data models, standards, ownership and custodianship, and pricing and cost recovery.

In this work, the systems development life cycle (SDLC) approach is adopted in both database and system development. SDLC is a generic description of the process of developing a software system in six phases, namely: planning, analysis, design, building, implementation and maintenance [12]. This approach to systems development is adopted as it provides mechanisms for system refinement and improvement in the course of system development. It is thus more realistic to build in a certain degree of flexibility in the SDLC to accommodate changes in the outcomes of one phase that are necessitated by findings in another phase.

\subsection{Database Modeling}

This involved the adaptation (mapping) of the LADM to capture the Kenyan context. The LADM has three basic packages: the party, the legal/administrative, and the spatial unit packages. These are implemented using four 
main classes; LA_Party, LA_RRR, LA_BAunit, and LA_SpatialUnit) as shown in Figure 4.

The adaptation of the LADM to the Kenya's systems was informed by the current land administration practice and prevailing regulations. Table 1 shows this mapping of the LADM basic classes to the Kenyan land administration system, while Figure 5 shows the resultant model, which we subsequently refer to as the "Africanized LADM" (A-LADM).

\subsection{System Modeling}

Traditionally, systems development has been technology-centered and application driven, focusing on hardware performance and software reliability. This was an effective means of managing large and complex systems development tasks involving close interaction between hardware limitations and application programs. The central concern in systems development today is not hardware performance, but rather systems usability or, as it is often called, user friendliness [12]. The new generation of systems is designed to be efficient and easy to use in order to improve the user's overall experience and productivity. As a result of the change in design focus and objectives, the conventional technology-centered concepts in systems development are being gradually abandoned in favor of what have come to be known as user-centered design (UCD) methodologies. This approach was adopted in this research.

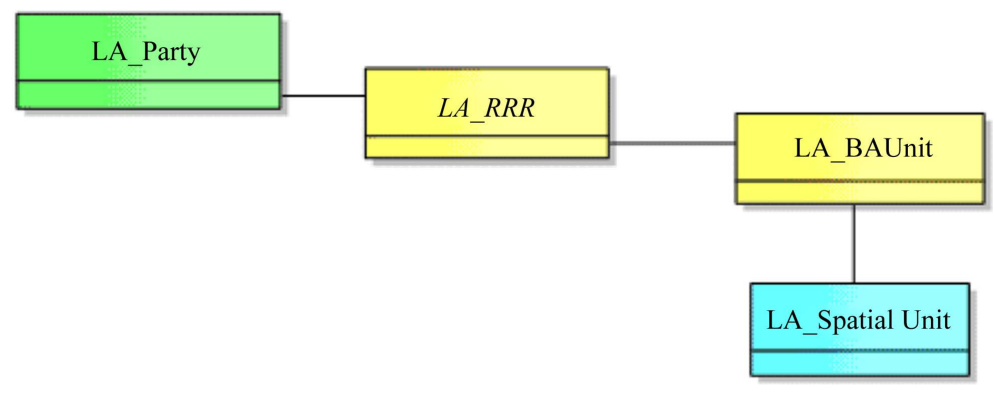

Figure 4. The LADM main packages.

Table 1. Mapping of LADM to Kenyan land data.

\begin{tabular}{|c|c|c|}
\hline LADM Classes & Kenya LIMS Classes & Description \\
\hline LA_Party & Owners & $\begin{array}{l}\text { Stores information about persons who have a right to land. This takes care of the other } \\
\text { specializations of owners, including group ownership, non-person or institutional ownership. }\end{array}$ \\
\hline \multirow{5}{*}{ LA_Spatial Unit } & Parcel & Stores information about land parcels. \\
\hline & Administration Class & It has information on counties. \\
\hline & Spatial Unit & This captures the various types of spatial entities that can be referenced in the system. \\
\hline & Registration Class & Land parcels belong to a registration section. This class stores all the registration sections. \\
\hline & Rights & This class stores information about all entitlements a person has on land. \\
\hline \multirow[t]{2}{*}{ LA_RRR } & Restrictions & $\begin{array}{l}\text { It stores information about encumbrances that refrain a person from enjoying his rights } \\
\text { on land. }\end{array}$ \\
\hline & Responsibilities & $\begin{array}{l}\text { This stores information about the obligations that the owner has with respect to other users, } \\
\text { the environment and the state. }\end{array}$ \\
\hline Landuse & Land Use & Land use zoning information is stored in this class. \\
\hline Valuation & Valuation & Land Valuation information is stored in this class. \\
\hline extTransaction & Transaction & $\begin{array}{l}\text { This class registers all transactions that result in change in parcel, admin unit, rights and } \\
\text { owner. }\end{array}$ \\
\hline extApplication & Application & This class records all applications lodged to the land administrators by land owners. \\
\hline extStaff & Staff & This is a class that stores information about employees who play a role in land transactions. \\
\hline
\end{tabular}




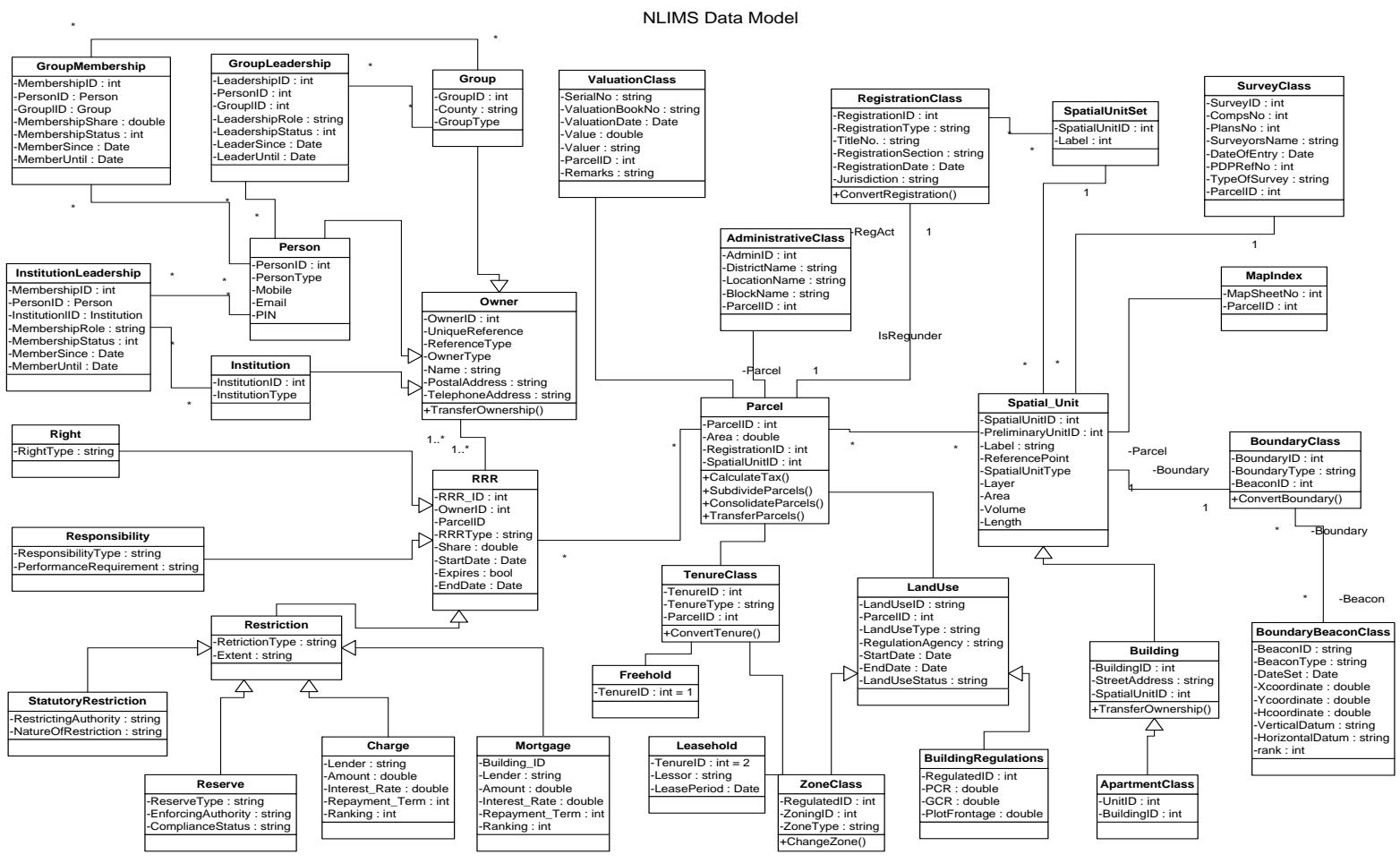

Figure 5. The africanized LADM for Kenya.

The system developed has used Service Oriented Architecture (SOA) principles and utilizes free and open source software (FOSS) as much as possible. The open source tools used for the implementation include: Dia (for Unified Modeling Language (UML) Modeling) [13], PostGIS [14] and PostgreSQL (for database development and management) [15]; QGIS (for GIS data preparation, management and cleaning) [16]; Liclipse (as the Integrated Development Environment) [17] and Leaflet [18], Mapnik [19], Geodjango \& Django (for the web map application development) [20]. Python programming language [21] was used for writing the code for the system implemented. This system was developed as a web application using the Django Python Framework tools.

The tools used in the implementation are listed in Figure 6. These tools range from modeling tools, database development and management tools, GIS data preparation, cleaning and management, Integrated Development Environment and Web application development tools.

\subsection{Implemented Workflow}

The pilot system, christened Land Administration System (LAS), has been designed to capture the "Application for approval of change of user" workflow, which is a workflow under the development control processes. In formulating and developing the workflows the following elements were considered, 1) the actors, 2) the processes (actions), 3) input data or triggers and 4) the output data. The output of one process can serve as the input of at least one subsequent or related process. These are presented schematically in Figure 7. Thus a complete workflow is the chaining together of various sub-processes (actions). The rationale in spending time to develop these workflows is informed by the reality that while having a robust data model is great, it is also very crucial to ensure that there is embedded in the solution the capacity to update the data automatically driven by the workflows identified. The system to at all times reflects the correct and current status of the land information.

The implemented LAS adapted the re-engineered application for Change of User development control process. This process involves receiving of an application for Change of User at the registry, assessment of fees by the development control unit, payment of fees, joint site visit by the relevant offices, such as land officer, physical planning, land survey, etc., reception of recommendations from the site visit to the approving authority. Prior to the reengineering, this workflow had 15 stages, which would take months to complete. The re-engineered 


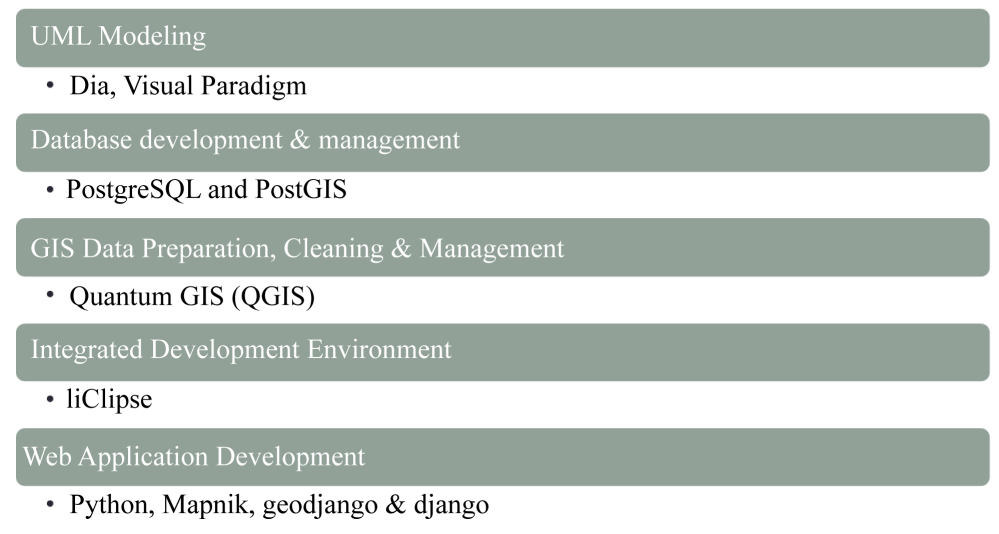

Figure 6. Various software components to be used in implementing the solution.

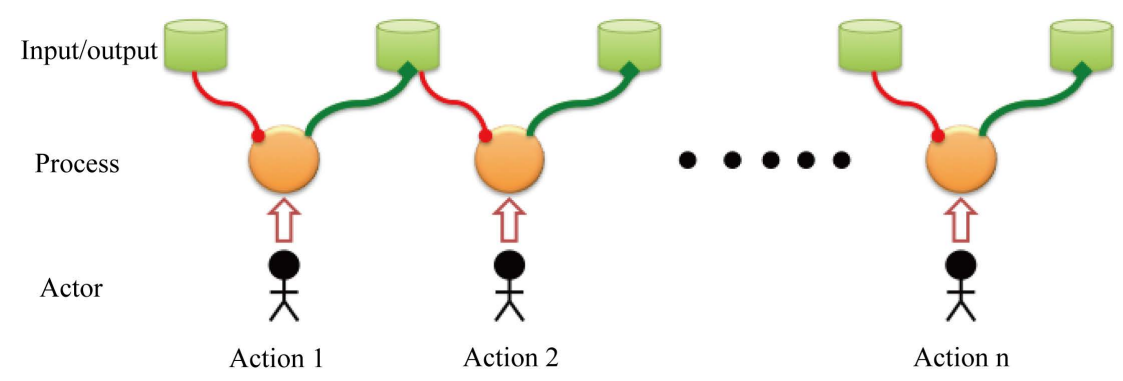

Figure 7. Workflow elements interplay.

processes have simplified the processes, removed duplicated and obsolete processes and collapsed these into fewer and more efficient processes thereby enhancing service delivery efficiency and effectiveness. This reengineered process has only five steps, and is anticipated to take a maximum of 17 days. The pilot system borrows from this reengineered process to simplify the existing processes. The developed LAS has automated this application process as well as facilitated the sequential processing of the documents, allowing online tracking of the progress of that application processing.

Figure 8 shows the workflow for change of user application. The actors involved are 1) the Registry: who receives the application, verifies that all required attachments have been provided, forwards to the technical team and communicates with the applicant, local authorities and the various state agencies requiring notification and information on the application; and 2) Development Control: which is the main technical unit charged with land development control. The unit examines all proposed developments on land. On receiving the application this unit evaluates the application and gives their approval or rejection of the proposed development detailing the reasons. Their approval or rejection report is then forwarded to the registry section who, communicates to the applicant and other state agencies requiring to be informed of the decision.

In the implementation, the Application Lifecycle is deemed as consisting of 3 components: 1) states, 2) input documents and 3) outputs.

The states are 1) UNVERIFIED: All new applications are unverified until verified by the registry. All applications that are unverified are listed under the Registry module. When the registry fails to verify an application, it remains unverified and the applicant is notified of the reason for the failure, 2) VERIFIED: Once all the documents and information provided are verified by the registry the application assumes the Verified Status. All verified applications are listed under the developments Control module, 3) APPROVED: Applications assigned the Approved status have been assessed by the Development control officers and successfully passed. Approved applications are listed under the Approved module, 4) REJECTED: The development control unit can reject an application if after the assessment they conclude it goes against the land-use planning regulations, and 5) COMPLETED: Marks the end of life of an application. Applications assume this state once communication has been made to the applicant and relevant authorities on the outcome of the assessment.

Inputs documents are supposed to be uploaded in the system from the web portal together with the application 


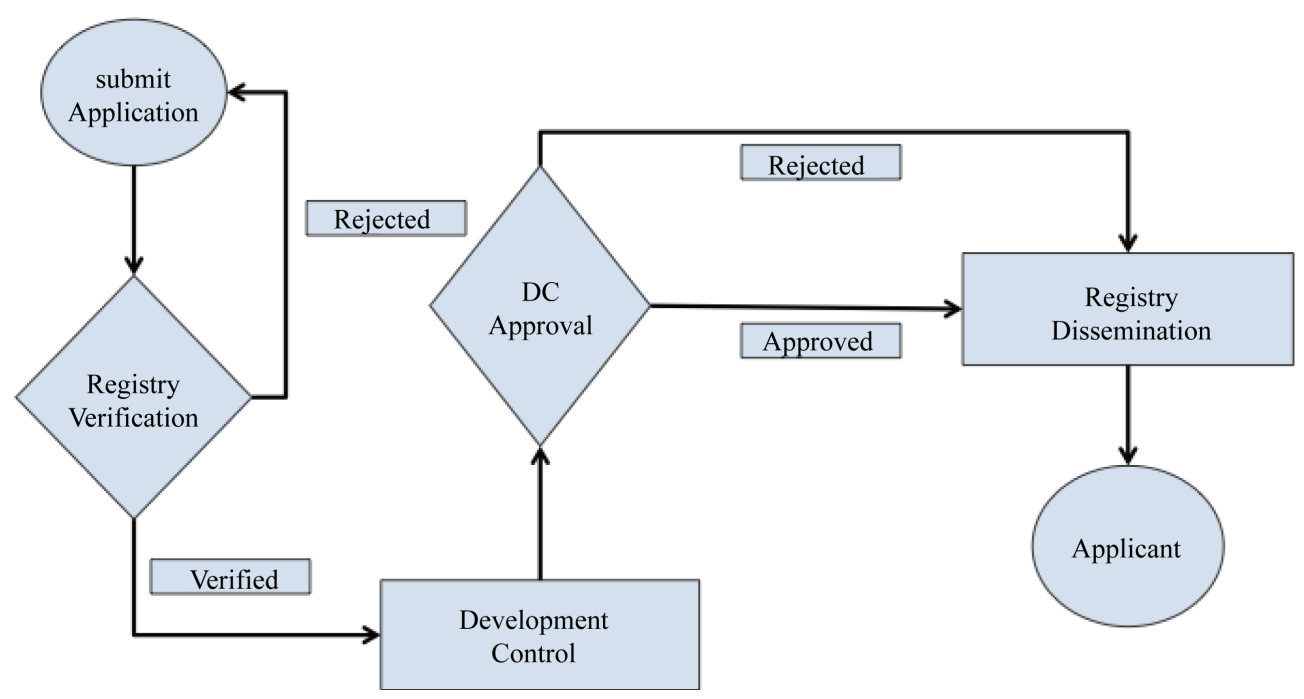

Figure 8. Application for Change of User workflow.

for it to be deemed a complete application. For this workflow, the documents required are: 1) Latest Search Document, 2) Title Certificate, 3) Comments form from Physical Planner, 4) Physical scheme plan, 5) Physical Planning Application (PPA) form no. 2, 6) Payment Receipt and 7) Planning Document.

The outputs of the process that are communicated to the applicant and the relevant authorities are: 1) development control comments, and 2) reports from the development control assessments.

\section{Results and Discussion}

The pilot LAS was shared with the stakeholders during the second workshop held in June 2015. This was close to the time the project itself was ending. This was monumental from a project management point of view that all planned activities had been concluded on time and all deliverables had been prepared and delivered. Of key importance was the pilot system, which was the evidence of the successful, modeling and system development. Some of the interfaces of this system are given in Figures 9-11. Not shown is the interface that allows one to lodge an application, track the processing of the application and finally notification of the outcome of the application.

During the validation workshop, a number of issues were raised and several suggestions were proffered on the system components and functionalities. Some of these include:

1) The workflow implemented left out key government personnel involved in approval processes. Examples are public health officials and road engineers, who are required to give comments on certain essential change of user applications.

2) The developed LAS is fully dependent on the internet and communication to the applicants is purely email based. It was suggested that the system should be improved to include communication via Short Message Service (SMS), which could automatically communicate to the clients on the processing progress and outcomes.

3) It was suggested that a backup solution is very essential for the data collected and stored in the system, and it needs to be incorporated.

4) There was need to introduce more security restrictions to prevent possible data and information manipulation by the wrong parties.

This feedback was used to improve on the prototype LAS, while those that could not be immediately implemented have been noted as part of the scaling -up opportunity for the long-term improvement.

With respect to the system web interfaces, the user experience feedback picked up the following issues and concerns about the way the web application solution works:

1) Web pages: Most of the users of the system were comfortable with the first glance of the LAS home page. There was satisfaction with the colors, content arrangement and position of links to other web pages of the system. Additionally the web users suggested that an FAQ (Frequently Asked Questions) web page that would act as a guide and reference while using the system should be there. 


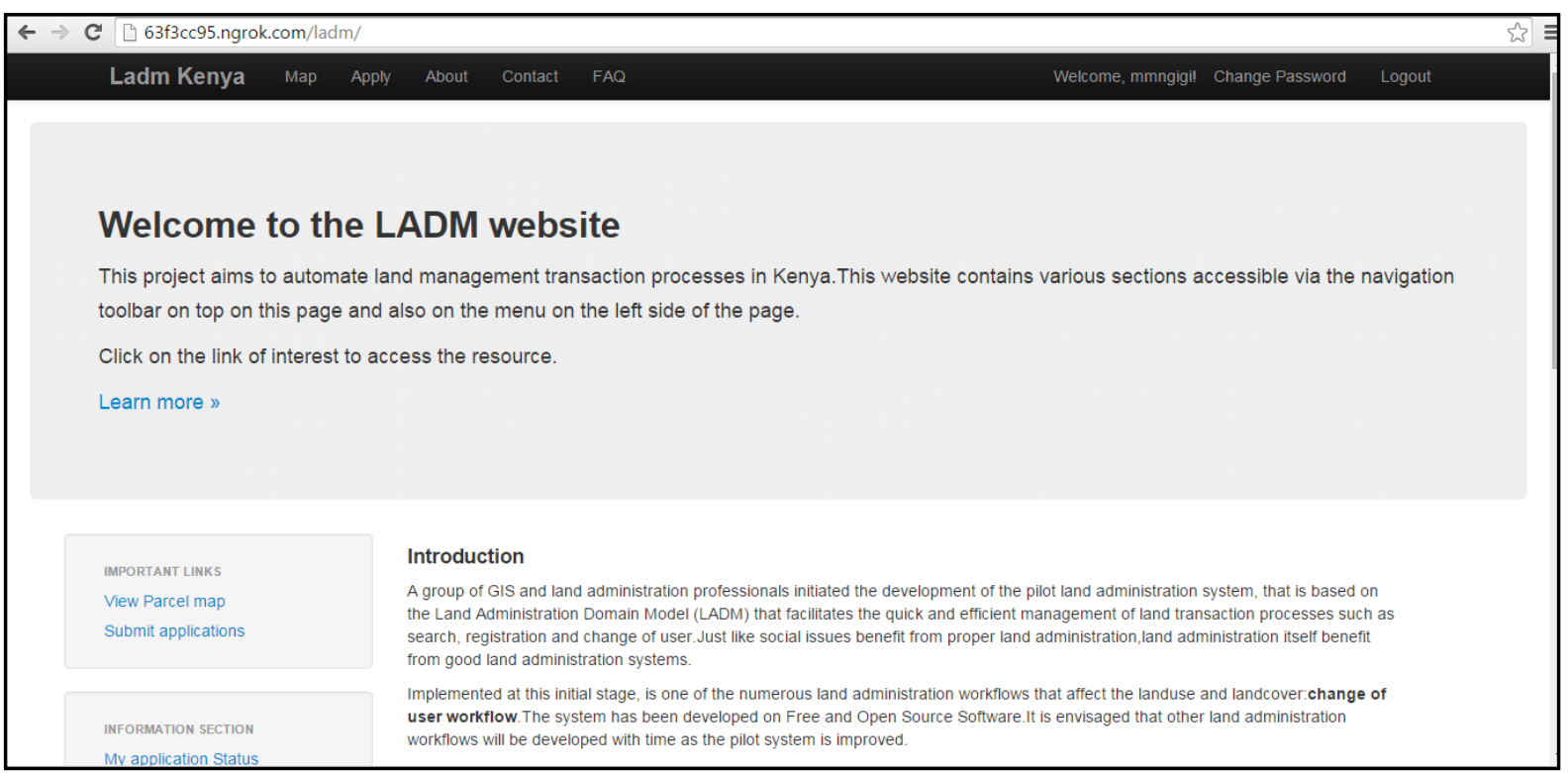

Figure 9. Welcome page of the pilot LAS.

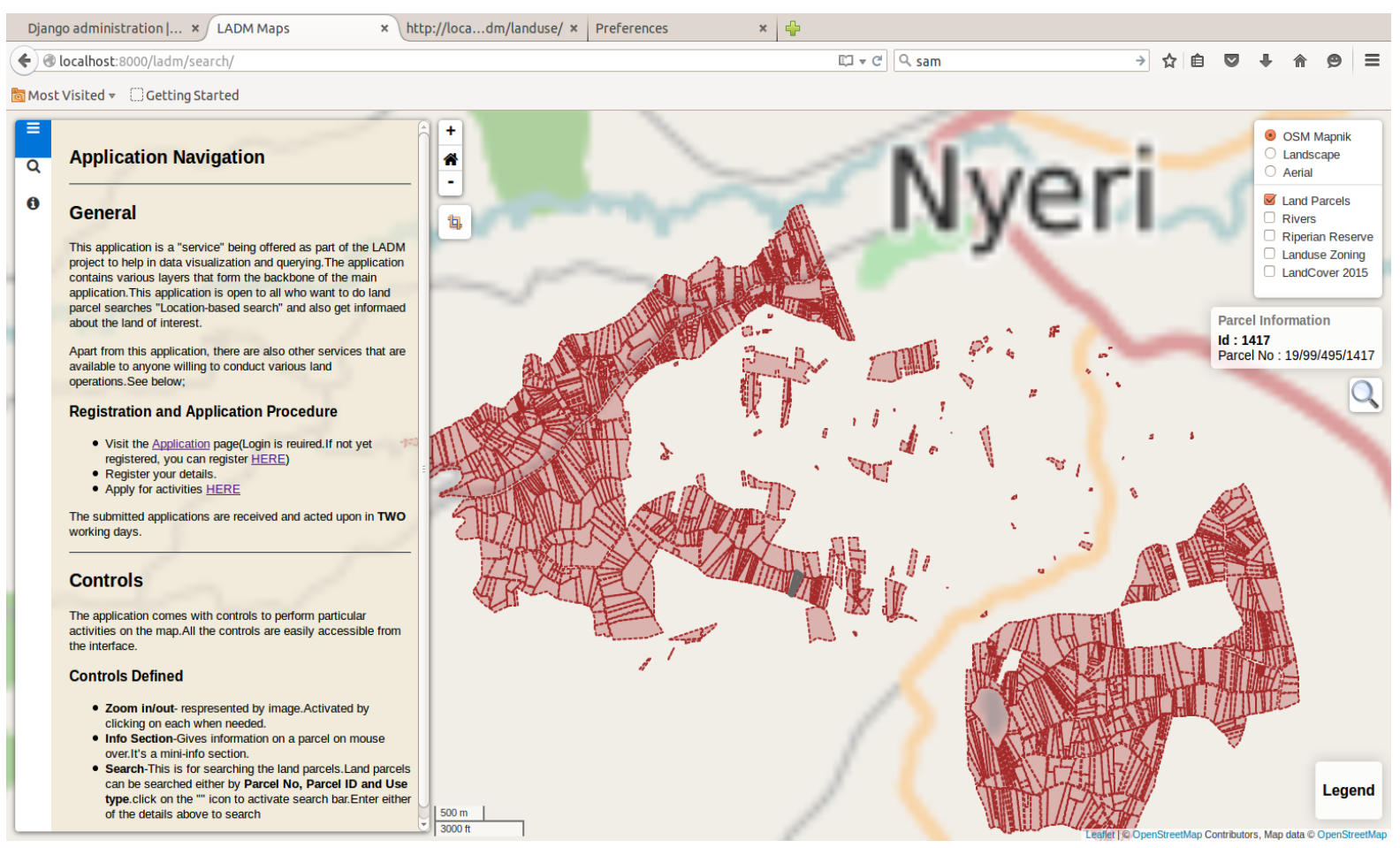

Figure 10. Parcel identification.

2) Data: It was noted that the LAS needed more data layers to be included for the system to work effectively. Information on the how the data was collected could also be included in the website as part of the metadata content.

3) Content: The users noted a few grammar errors on both the front and the back-end of the system. These were corrected to improve the user friendliness of the LAS website. It was also noted that the LAS site was available only in English, and it was suggested that it should be availed in Kiswahili also, with simple and clear diagrams that illustrated how the system worked. 


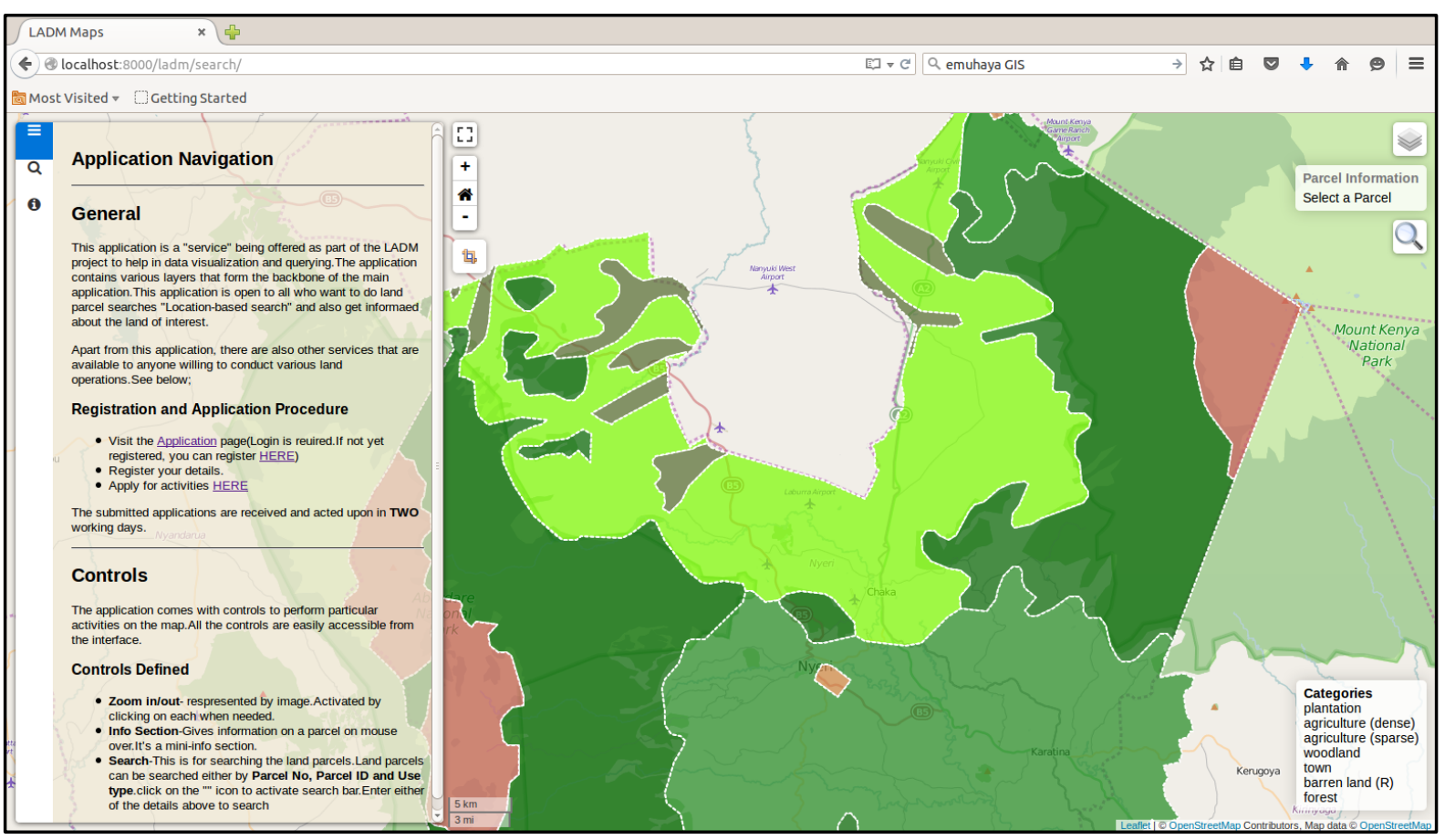

Figure 11. Land use zones.

The prototype LAS developed implemented only the "Application of Change of User" process of the development control in land administration. For the system to be beneficial to the community that it is meant to serve, it is of essence that the prototype gets up-scaled. There needs to be in place, good strategic planning for the up scaling process. The scaling up strategy needs to be incremental and continuous over time, allowing the system to evolve in terms of its offerings. The key elements in this upscaling should be: system improvement, resource team and supporting organizations. Dissemination of information and data, organization of upscaling process, resource required, and monitoring are essential for the success of the scaling up strategy

\section{Conclusions}

The main deliverable was the pilot system developed towards the end of the project. This is a web based land administration systems managing the process of change of user. This process is representative of how the all the other processes involved in land administration can be implemented. The system employs a centralized database, which holds the spatial units, the land records (documents) and information about the parties involved in land administration. The system features paperless transactions in the land administration. The pilot system is important in addressing the issues of automation of land information management in the Kenya. Digitizing the land administration transactions and elimination of paper records means a lot as flaws that regularly occur are eliminated and confidence in the processes will as a consequence be bolstered.

Alongside with the application, this research produced a comprehensive report on the implementation of the LADM standard in the Kenyan Land administration sector. This report addresses generic issues covering the opportunities that are available and the challenges. This report is adaptable to any other developing country especially those with similar structure as Kenya in their land administration domain.

Other deliverables are the analyses reports on the various workflows, the user requirements document, the adapted Land Administration Domain Model and the methodology for implementation of the system. These are important in addressing the issues of automation of land information management in the region. Good and efficient land information management is acknowledged as one of the key drivers of sustainable development and forms the basis for a strong and sustained National Spatial Data Infrastructure (NSDI). Part of the infrastructure that has been used to host the pilot system will be reused for the NSDI when implemented, thereby reducing potential for redundancies and duplication of efforts and data. 


\section{Acknowledgements}

The research for this project was made possible through the generous support of the American people managed by USAID through its RCMRD/SERVIR-Eastern and Southern Africa Small Grants Program.

\section{References}

[1] Siriba, D.N., Voss, W. and Mulaku, G.C. (2011) The Kenyan Cadastre and Modern Land Administration. Zeitschrift fur Vermessungswesen, 136, 177-186.

[2] Kuria, D., Mwangi, N. and Ngigi, M. (2010) A Prototype Digital Cadastral Information System for the Survey of Kenya. Proceedings of the Applied Geoinformatics for Society and Environment Conference (AGSE 2010), Arequipa, 3-6 August 2010, 167-173.

[3] Government of Kenya (2009) The National Land Policy. Government Printers, Nairobi

[4] Lemmen, C. (2012) A Domain Model for Land Administration. PhD Thesis, Technische Universiteit Delft, Delft.

[5] Kaufmann, J. and Steudler, D. (1998) Cadastre 2014: A Vision for a Future Cadastral System. FIG 167-173.

[6] Lemmen, C. and van Oosterom, P. (2013) The Land Administration Domain Model Standard. Proceedings of the 5th Land Administration Domain Model Workshop, Kuala Lumpur, 24-25 September 2013, 11-30.

[7] Government of Kenya (2010) The Constitution of Kenya. Government Printers, Nairobi.

[8] Government of Kenya (2012) The National Land Commission Act. Government Printers, Nairobi.

[9] Williamson, I., Enemark, S., Wallace, J. and Rajabifard, A. (2010) Land Administration for Sustainable Development. ESRI Press Academic, Redlands.

[10] Government of Kenya (2012) The Land Act. Government Printers, Nairobi.

[11] Government of Kenya (2012) The Land Registration Act. Government Printers, Nairobi.

[12] Yeung, A.K.W. and Hall, G.B. (2007) Spatial Database Systems: Design, Implementation and Project Management. Springer, Dordrecht.

[13] McCann, W.J. (2013) Dia. https://wiki.gnome.org/Apps/Dia

[14] Marquez, A. (2015) PostGIS Essentials. Parkt Publishing, Birmingham.

[15] Chauhan, C. (2015) PostgreSQL Cookbook. Parkt Publishing, Birmingham.

[16] Sherman, G. (2012) The Geospatial Desktop: Open Source GIS and Mapping. Locate Press, British Columbia.

[17] Brainwy Software (2015) LiClipse. http://www.liclipse.com

[18] Agafonkin, V. (2015) Leaflet: An Open-Source JavaScript Library for Mobile-Friendly Interactive Maps. http://leafletjs.com/reference.html

[19] Pavlenko, A. (2015) Mapnik: The Core of Geospatial Visualization \& Processing. http://mapnik.org

[20] Django Software Foundation (2015) Django Documentation. https://docs.djangoproject.com/en/1.9/

[21] Westra, E. (2015) Python Geospatial Analysis Essentials. Parkt Publishing, Birmingham. 